\title{
Obstructive sleep apnoea in patients with obesity and hypertension
}

\author{
Antonino Di Guardo, Gaetano Profeta, Cristiano Crisafulli, Giuseppe Sidoti, \\ Marcello Zammataro, Italo Paolini and Alessandro Filippi
}

\begin{abstract}
\section{Background}

The links between obstructive sleep apnoea and hypertension are well established; obstructive sleep apnoea is reported in up to $30 \%$ of patients with hypertension, although it is frequently underdiagnosed. Physicians can assess the degree of sleepiness by administering the Epworth Sleepiness Scale, but the large number of patients with hypertension makes this strategy difficult for busy physicians to implement. Obese patients form a subgroup at higher risk for obstructive sleep apnoea, which can be targeted for screening.
\end{abstract}

Aim

The study carried out a preliminary exploration of the effectiveness of screening patients with hypertension and obesity for obstructive sleep apnoea in general practice using the Epworth Sleepiness Scale.

\section{Setting}

One group practice in Italy.

\section{Design of study}

'Good clinical practice' was systematically applied: identification of patients with hypertension and obesity; qualitative interview to identify obstructive sleep apnea; and consequent work-up and therapy.

\section{Method}

Three family physicians, caring for 769

pharmacologically-treated patients with hypertension, identified 220 obese patients without relevant pulmonary or neurological diseases or insomnia; 31 of these 220 patients scored $>11$ on the Epworth Sleepiness Scale.

\section{Results}

Polysomnography confirmed obstructive sleep apnoea in $10 \%$ of the obese, hypertensive population $(95 \%$ confidence interval $[\mathrm{Cl}]=7.03 \%$ to $13.63 \%$ ), and in $3.9 \%$ of the whole hypertensive population $(95 \% \mathrm{Cl}=$ $2.74 \%$ to $5.51 \%$ ). At baseline, 24-hour blood pressure monitoring showed uncontrolled blood pressure in all these patients. Under continuous positive airway pressure (CPAP), the blood pressure value normalised $(P<0.05)$, and the mean Epworth Sleepiness Scale score decreased significantly: mean 13.68 versus 7.84 $(P<0.001)$.

\section{Conclusion}

In obese patients with hypertension examined in this study, the prevalence of obstructive sleep apnoea prevalence is about $10 \%$. CPAP significantly ameliorates the blood pressure control. This simple screening and treatment strategy may be easily adopted in primary care.

\section{Keywords}

continuous positive airway pressure; diagnosis; hypertension; obesity; obstructive; sleep apnea.

\section{INTRODUCTION}

Obstructive sleep apnoea affects $5 \%$ of the adult population, ${ }^{1}$ and is characterised by collapse of the upper airway resulting from the loss of waking neuromuscular drive as the brain changes from wakefulness to sleep. The links between obstructive sleep apnoea and high blood pressure are well established, particularly among patients with resistant hypertension; ${ }^{2}$ and obstructive sleep apnoea is reported in up to $30 \%$ of patients with hypertension, although it is frequently underdiagnosed. $^{3-7} \quad$ Long-term treatment of obstructive sleep apnoea by continuous positive airway pressure (CPAP) has been shown to improve blood pressure control, even in patients with refractory hypertension. ${ }^{7}$

The role of obstructive sleep apnoea in hypertension has been recognised by the European 2007 Guidelines for the Management of Arterial Hypertension, ${ }^{8}$ which state that '... this syndrome may contribute to the elevated pressure in a large proportion of hypertensive patients' and that 'untreated obstructive sleep apnoea may have direct and deleterious effects on cardiovascular function and structure'. Identification of obstructive sleep apnoea in patients with hypertension is therefore an important target in clinical practice. Unfortunately, neither the European guidelines ${ }^{8}$ nor the American

A Di Guardo, GP; G Profeta, GP; C Crisafulli, GP; I Paolini, GP; A Filippi, GP, Italian College of General Practitioners, Florence, Italy. G Sidoti, sleep-disorders specialist; M Zammataro, sleep-disorders specialist, DEA's Department of Internal Medicine, 'Garibaldi' Hospital, Catania, Sicily, Italy.

Address for correspondence

Dr Alessandro Filippi, Italian College of General

Practioners, Via del Pignoncino, 9/11 -50142-Florence, Italy. E-mail: filippi.alessandro@simg.it

Submitted: 21 August 2009; Editor's response: 23 October 2009; final acceptance: 16 December 2009.

(c)British Journal of General Practice 2010; 60: 325-328.

DOI: 10.3399/bjgp10X484174 


\section{How this fits in}

Obstructive sleep apnoea may contribute to elevated blood pressure in a large proportion of patients with hypertension. Although continuous positive airway pressure has been shown to improve blood pressure control in patients with obstructive sleep apnoea, this problem remains under-diagnosed. The Epworth Sleepiness Scale is a simple tool that may help to identify obstructive sleep apnoea in general practice. Screening obese patients with hypertension with this tool is feasible and permits diagnosis and treatment of obstructive sleep apnoea in about $10 \%$ of these patients.

Heart Association/American College of Cardiology (AHA/ACC) Foundation Scientific Statement ${ }^{9}$ suggests any strategy to detect obstructive sleep apnoea in clinical practice, while the seventh report of the Joint National Committee on Prevention, Detection, Evaluation, and Treatment of High Blood Pressure (also referred to as the 'JNC 7') implicates obstructive sleep apnoea as a secondary cause of hypertension. ${ }^{10}$

A simple strategy to identify obstructive sleep apnoea in patients with hypertension could be extremely useful in general practice, allowing blood pressure to be reduced in many patients with 'hard-to-control' hypertension. Physicians can effectively and easily assess the degree of sleepiness by administering the Epworth Sleepiness Scale, ${ }^{11}$ a simple, self-administered questionnaire, which provides a measurement of the patient's general level of daytime sleepiness (a moderate/severe score indicates the need of a diagnostic polysomnography). Clinical suspicions

\section{Box 1. Epworth Sleepiness Scale. ${ }^{11}$}

\section{Situations}

1. Sitting and reading

2. Watching TV

3. Sitting inactive in a public place (for example, a theatre or a meeting)

4. As a passenger in a car for an hour without a break

5. Lying down to rest in the afternoon when circumstances permit

6. Sitting and talking to someone

7. Sitting quietly after lunch without alcohol

8. In a car, while stopped for a few minutes in traffic

Points: $0-10=$ normal; $11-14=$ mild $; 15-18=$ moderate; $19-24=$ severe

Would never doze: 0

Slight chance of dozing: 1

Moderate chance of dozing: 2

High chance of dozing: 3 of obstructive sleep apnoea must always be confirmed by polysomnography.

Obesity is associated with a fourfold higher prevalence of obstructive sleep apnoea. ${ }^{12}$ Patients with obesity and hypertension can be easily identified, frequently visit their GPs, and their combination of conditions may represent the first target to detect and treat obstructive sleep apnoea in primary care.

The aim of the present study was to detect obstructive sleep apnoea among patients with obesity and hypertension and to treat hypertension accordingly. The participating GPs agreed on the need to evaluate the feasibility of this strategy and to verify the effect of treatment of obstructive sleep apnoea on blood pressure control.

\section{METHOD}

Three GPs, caring for a total of 4514 people (aged $\geq 18$ years) decided to improve blood pressure control in obese hypertensive individuals. They identified obstructive sleep apnoea as an important problem in this group of patients, and the Epworth Sleepiness Scale (Box 1$)^{11}$ as a simple tool for initial screening of obstructive sleep apnoea. First they identified all their patients with hypertension on stable pharmacological treatment. To simplify the screening, the GPs decided to exclude patients with relevant pulmonary or neurological diseases, or those affected by insomnia. All the remaining obese patients (body mass index [BMl] $>30 \mathrm{~kg} / \mathrm{m}^{2}$ ) with hypertension were tested with the Epworth Sleepiness Scale.

All the patients with an Epworth Sleepiness Scale score greater than 11 points ${ }^{11}$ underwent an overnight polysomnography and 24-hour ambulatory blood pressure monitoring. Overnight polysomnography ('SOMNOcheck effort' polysomnograph, Weinmann, Germany) was performed between 22.00 and 06.00 at the local sleep-disorder medicine department at Garibaldi Hospital, Catania, Italy. A diagnosis of obstructive sleep apnoea was established following the guidelines of the Institute for Clinical Systems Improvement. ${ }^{13}$ Blood pressure recordings were performed by GPs using a non-invasive device (Takeda TM-2430, A\&D Medical, Tokyo, Japan) validated by the British Hypertension Society (grade AA for approved hospital grade accuracy), ${ }^{14}$ according to the standards of the British Hypertension Society, ${ }^{14}$ before treatment of the obstructive sleep apnoea. Blood pressure was evaluated according to the European Society of Hypertension recommendations. ${ }^{8}$ All patients with a diagnosis of obstructive sleep apnoea were offered appropriate lifestyle counselling and auto-adjusting 
nasal CPAP (SOMNOsmart 2, Weinmann, Hamburg, Germany), if this was considered appropriate by the specialist. It was also planned to repeat the Epworth Sleepiness Scale, polysomnography, and 24-hour ambulatory blood pressure monitoring for all patients prescribed CPAP.

Statistical analysis was performed using SPSS (version 10.0). Student's $t$-test was used to evaluate differences before and after CPAP treatment. Statistical significance was assumed at $P \leq 0.05$. Data are reported as means and standard deviations (SD) unless otherwise stated.

\section{RESULTS}

The GPs cared for 769 patients with hypertension (210 males with a mean age of 57.46 years [SD 14.88], and 559 females with mean age of 53.55 years [SD 16.64]). Obesity was present in 305 patients, all on stable therapy; 85 were affected by relevant pulmonary or neurological diseases or insomnia and were excluded from further evaluation. The 220 remaining patients were tested with the Epworth Sleepiness Scale to identify obstructive sleep apnoea.

Thirty-one patients scored $>11$ points, and polysomnography confirmed the diagnosis of obstructive sleep apnoea in 30 patients: 17 males aged 52.82 years (SD 9.81) with BMI $37.45 \mathrm{~kg} / \mathrm{m}^{2}$ (SD 7.85); and 13 females aged 53.93 years (SD 10.54) with BMI $42.07 \mathrm{~kg} / \mathrm{m}^{2}$ (SD 6.27). These patients represent $10 \%$ (95\% confidence interval $[\mathrm{Cl}]=7.03 \%$ to $13.63 \%$ ) of the observed obese hypertensive population and $3.9 \%(95 \% \mathrm{Cl}=$ $2.74 \%$ to $5.51 \%$ ) of the whole stable hypertensive population. All these 30 patients accepted the use of CPAP, and no-one discontinued the treatment.

After 12 weeks of CPAP, all patients were reevaluated; in the intervening period, no significant weight loss was observed and there were no changes in drug therapy. The results of 24-hour blood pressure monitoring at baseline and after CPAP are summarised in Table 1; all differences between values at baseline and after CPAP were statistically significant (from $P<0.05$ to $P<0.001$ ). The mean Epworth Sleepiness Scale score also decreased significantly: from 15.94 (SD 4.65) to 10.45 (SD 3.25) points $(P<0.001)$.

\section{DISCUSSION}

\section{Summary of main findings}

Use of the Epworth Sleepiness Scale in obese patients with hypertension identified obstructive sleep apnoea in about $10 \%$ of patients and the diagnosis was confirmed by polysomnography in all but one patient. All patients with obstructive sleep apnoea were considered suitable for CPAP. The use of nasal CPAP in these patients greatly improved blood pressure control in all cases.

\section{Strengths and the limitations of this study}

The most important limitation of the study is the small number of participating GPs and, therefore, examined patients. It is probable that the detection strategy missed some obstructive sleep apnoea among patients with hypertension. On the other hand, the aim of the audit was not identification of the patients with hypertension and obstructive sleep apnoea, but to implement and test a simple strategy to identify some of them. In the authors' opinion, this approach is feasible in everyday practice and permits a useful improvement when compared with the actual practice of episodic or occasional diagnosis of obstructive sleep apnoea. A possible strength of the study is the completeness of the data: all the patients with hypertension on stable pharmacological therapy were considered, and all the patients with suspected obstructive sleep apnoea underwent further treatment.

\section{Comparison with existing literature}

The role of obstructive sleep apnoea in hypertension has been recognised by the European 2007 Guidelines for the Management of Arterial

\section{Table 1. Results of 24-hour blood pressure monitoring at baseline and after} continuous positive airway pressure (CPAP).

\begin{tabular}{|c|c|c|c|c|c|c|}
\hline & \multicolumn{3}{|c|}{ Baseline, $\mathrm{mmHg}$} & \multicolumn{3}{|c|}{ After CPAP, mmHg } \\
\hline & $\begin{array}{c}\text { Mean blood } \\
\text { pressure }\end{array}$ & $\begin{array}{l}\text { Systolic blood } \\
\text { pressure }\end{array}$ & $\begin{array}{c}\text { Diastolic blood } \\
\text { pressure }\end{array}$ & $\begin{array}{l}\text { Mean blood } \\
\text { pressure }\end{array}$ & $\begin{array}{l}\text { Systolic blood } \\
\text { pressure }\end{array}$ & $\begin{array}{c}\text { Diastolic blood } \\
\text { pressure }\end{array}$ \\
\hline \multicolumn{7}{|c|}{ Daytime } \\
\hline Mean & 103.6 & 140.1 & 86.4 & 93.6 & 132.1 & 75.8 \\
\hline SD & 16.1 & 17.6 & 16.1 & 11.3 & 15.7 & 11.6 \\
\hline \multicolumn{7}{|c|}{ Night-time } \\
\hline Mean & 96.2 & 129.9 & 79.1 & 85.9 & 118.5 & 69.6 \\
\hline SD & 17.6 & 20.0 & 17.0 & 10.9 & 13.9 & 10.1 \\
\hline
\end{tabular}

All differences between values at baseline and after CPAP were statistically significant (from $\mathrm{P}<0.05$ to $\mathrm{P}<0.001$ ). 
Hypertension. ${ }^{8}$ Unfortunately, neither the European guidelines, ${ }^{8}$ nor the AHA/ACC Foundation Scientific Statement $^{9}$ suggests a strategy to detect obstructive sleep apnoea in clinical practice. By being aware of the symptoms, predisposing factors, and comorbidities associated with obstructive sleep apnoea, primary care providers can play a vital role in screening their patients.

Medical providers can assess the degree of sleepiness very effectively and easily by administering the Epworth Sleepiness Scale, ${ }^{11}$ but polysomnography is always required to confirm the diagnosis of obstructive sleep apnoea. The Epworth Sleepiness Scale is also the preferred method to assess degree of residual sleepiness after treatment initiation. ${ }^{11}$ In the authors' opinion, testing all patients with hypertension using the Epworth Sleepiness Scale is neither adequately supported by scientific evidence, nor feasible in usual care, at least in Italy. Only simple diagnostic strategies, focused on a limited number of individuals, can be implemented by busy physicians caring for hundreds of patients with hypertension.

Obesity is associated with a fourfold higher obstructive sleep apnoea prevalence, ${ }^{12}$ affects only a minority of patients with high blood pressure, and can be immediately suspected and assessed. Obese patients with hypertension can therefore be suitably targeted for obstructive sleep apnoea screening. As far as the authors know, such a strategy has not yet been tested in clinical practice.

\section{Implications for clinical practice and future research}

The Epworth Sleepiness Scale can be easily used to identify obstructive sleep apnoea among patients with obesity and hypertension in primary care. About $10 \%$ of these patients are consequently diagnosed with this disorder. CPAP may reduce high blood pressure in this subgroup of patients, possibly avoiding the use of additional antihypertensive drugs. This simple screening strategy may be easily adopted by GPs in everyday practice, thus benefiting thousands of patients nationwide. Such a generalised effort would be recommended if other larger studies confirm the current results.

\section{Ethical approval}

The authors applied 'good clinical practice', so formal approval was not necessary; therefore, this study has simply been notified to the Ethical Committee of Catania, which did not raise any objection.

\section{Competing interests}

The authors have stated that there are none.

\section{Discuss this article}

Contribute and read comments about this article on the Discussion Forum: http://www.rcgp.org.uk/bjgp-discuss

\section{REFERENCES}

1. Young T, Peppard P, Gottlieb D. The epidemiology of obstructive sleep apnoea: a population health perspective. Am J Respir Crit Care Med 2002; 165(9): 1217-1239.

2. Epstain M. Resistant hypertension: prevalence and evolving concepts. J Clin Hypertens 2007; 9(1 Suppl 1): 2-6.

3. Fletcher EC, DeBehnke RD, Lovoi MS, Gorin AB. Underdiagnosed sleep apnoea in patients with essential hypertension. Ann Intern Med 1985; 103(2): 190-195.

4. Kales A, Bixler EO, Cadieux RJ, et al. Sleep apnoea in a hypertensive population. Lancet 1984; 2(8410): 1005-1008.

5. Lavie P, Ben-Yosef R, Rubin AE. Prevalence of sleep apnoea syndrome among patients with essential hypertension. Am Heart J 1984; 108(2): 373-376.

6. Vardan S, Dunsky MH, Hill NE, et al. Systemic systolic hypertension in the elderly: correlation of hemodynamics, plasma volume, renin, aldosterone, urinary metanephrines and response to thiazide therapy. Am J Cardiol 1986; 58(10): 1030-1034.

7. Williams AJ, Houston D, Finberg S, et al. Sleep apnoea syndrome and essential hypertension. Am J Cardiol 1985; 55(8): 1019-1022.

8. Mancia G, De Backer G, Dominiczak A, et al. 2007 Guidelines for the Management of Arterial Hypertension: The Task Force for the Management of Arterial Hypertension of the European Society of Hypertension (ESH) and of the European Society of Cardiology (ESC). J Hypertens 2007; 25(6): 1105-1187.

9. Somers VK, White DP, Amin R, et al. Sleep apnea and cardiovascular disease: an American Heart Association/American College of Cardiology Foundation Scientific Statement From the American Heart Association Council for High Blood Pressure Research Professional Education Committee, Council on Clinical Cardiology, Stroke Council, and Council on Cardiovascular Nursing in Collaboration with the National Heart, Lung, and Blood Institute National Center on Sleep Disorders Research (National Institutes of Health). J Am Coll Cardiol 2008; 52(8): 686-717.

10. US Department of Health and Human Services. The Seventh Report of the Joint National Committee on Prevention, Detection, Evaluation, and Treatment of High Blood Pressure. NIH Publication No 04-5230, 2004.

http://www.nhlbi.nih.gov/guidelines/hypertension/jnc7full.pdf (accessed 6 Jan 2010).

11. Doghramji PP. Recognition of obstructive sleep apnoea and associated excessive sleepiness in primary care. J Fam Pract 2008; 57(8 Suppl): S17-23.

12. Kapa S, Kuniyoshi FHS, Somers VK. Sleep apnoea and hypertension: interactions and implications for management. Hypertension 2008; 51(3): 605-608.

13. Institute for Clinical Systems Improvement. Health care guideline: diagnosis and treatment of obstructive sleep apnoea. 6th edn. Bloomington, MN: Institute for Clinical Systems Improvement, 2008.

14. O'Brien E, Waeber B, Parati G et al. Blood pressure measuring devices: recommendations of the European Society of Hypertension. BMJ 2001; 322(7285): 531-536. 